\title{
Meta-Analysis of Clipping versus Coiling for the Treatment of Unruptured Middle Cerebral Artery Aneurysms: Direct Comparison of Procedure-Related Complications
}

This article was published in the following Dove Press journal:

Neuropsychiatric Disease and Treatment

\author{
Wen-qiang Xin' \\ Qi-qiang $X_{i n}^{2}$ \\ Xin-yu Yang'
}

'Department of Neurosurgery, Tianjin Medical University General Hospital, Tianjin 300052, Peoples Republic of China; ${ }^{2}$ Department of Preventive Medicine, School of Public Health, Nanchang University, Nanchang, Jiangxi 330000, Peoples Republic of China
Correspondence: Xin-yu Yang Department of Neurosurgery, Tianjin Medical University General Hospital, Tianjin 300052, Peoples Republic of China Tel +86- 18622766038

Fax +86-02260362062

Email yangxinyu@tmu.edu.cn
Background: Endovascular coiling and surgical clipping are routinely used to treat unruptured middle cerebral artery aneurysms (MCAAs). However, the optimal treatment for unruptured MCAAs is controversial. We aimed to systematically and comprehensively compare the clinical outcomes between endovascular coiling and surgical clipping for the treatment of MCAAs.

Method: This meta-analysis retrieved academic articles comparing the clinical outcomes between endovascular coiling and surgical clipping for unruptured MCAAs from the Cochrane Library, Medline, PubMed, and EMBASE databases. The reference articles of the identified studies were carefully reviewed to ensure that all available articles were represented in the study. The meta-analysis was conducted in accordance with the acknowledged the prioritized reported items for systematic review and meta-analysis (PRISMA) guidelines.

Results: A total of 6 studies, which enrolled a total of 789 participants, were included in our analysis. Of these 789 patients with MCAAs, 144 were assigned to an endovascular coiling group, and 645 were assigned to a surgical clipping group. Our results demonstrated that endovascular coiling was associated with a higher rate of retreatment $(\mathrm{OR}=104.926 ; 95 \% \mathrm{CI}$ : 12.931 to $851.379 ; \mathrm{P}<0.001)$ and postoperative complications $(\mathrm{OR}=3.157 ; 95 \% \mathrm{CI}: 1.239$ to 8.048; $\mathrm{P}=0.016$ ) than surgical clipping, especially for postoperative thrombus without infarction $(\mathrm{OR}=4.905,95 \% \mathrm{CI}: 1.097$ to $21.933 ; \mathrm{P}=0.037)$. Furthermore, surgical clipping was related to a higher rate of complete occlusion $(\mathrm{OR}=0.349,95 \% \mathrm{CI}: 0.140$ to $0.872 ; \mathrm{P}=0.024)$ and Glasgow Outcome Scale (GOS) $\geq 4(\mathrm{OR}=0.250 ; 95 \% \mathrm{CI}: 0.072$ to $0.867 ; \mathrm{P}=0.029)$ than endovascular coiling after the operation. However, there was no significant difference in the rate of death, the proportion of patients with modified Rankin Scale $(\mathrm{mRS})>2$, infarction, or bleeding. Conclusion: Although this study has inherent limitations, surgical clipping of unruptured MCAAs resulted in significantly higher complete aneurysm occlusion and GOS $\geq 4$ rates and was associated with a lower incidence of retreatment and complication, especially for postoperative thrombus without infarction. Therefore, the effect induced by surgical clipping of unruptured MCAAs remains superior to that induced by endovascular coiling; surgical clipping should be regarded as the first choice of treatment for unruptured MCAAs.

Keywords: endovascular coiling, surgical clipping, unruptured cerebral aneurysms

\section{Introduction}

Cerebral aneurysms are common diseases and the middle cerebral artery (MCA) is a relatively common site for intracranial cerebral aneurysms, accounting for $14.4 \%$ to $43 \%$ of all diagnosed aneurysms. ${ }^{1-4}$ Subarachnoid hemorrhage $(\mathrm{SAH})$ is one of the 
most dangerous complications of intracranial aneurysms rupture. Therefore, prophylactic treatment of unruptured cerebral aneurysms is necessary. ${ }^{5}$ However, the best therapy for unruptured intracranial aneurysms remains largely unknown. ${ }^{6}$ Surgical clipping is the primary treatment for aneurysms of the MCA in most centers. ${ }^{7-9}$ In a study by Rodriquez-Hernandez et al, which included 543 patients with middle cerebral artery aneurysms (MCAAs), the authors were able to achieve a $98 \%$ aneurysm occlusion rate, meaning that the results of microsurgical clipping were highly satisfying. ${ }^{10}$ Furthermore, endovascular coiling has increasingly been advocated as an alternative treatment for surgical clipping in unruptured aneurysms. ${ }^{11}$ As documented by Mortimer et al, ${ }^{12}$ the feasibility of MCAA coiling as the main treatment was shown to be approximately $95.8 \%$, demonstrating that endovascular treatment of MCAAs had an acceptable safety profile. Regarding the lack of consensus on which treatment provides sufficient safety, we conducted this meta-analysis of randomized and nonrandomized controlled trials to compare surgical clipping and endovascular coiling in terms of contemporary occlusion outcomes and complication rates in patients with unruptured intracranial aneurysms in the MCA.

\section{Materials and Methods Literature Search Strategy}

The PubMed, Cochrane Library, EMBASE, and Medline electronic databases were searched to identify all the publications (RCTs and non-RCTs) that compared surgical clipping with endovascular coiling for patients with unruptured MCAAs from the inception of the electronic databases to July 2019. We used the following keywords in combination with Boolean logic: surgical clipping, endovascular coiling, middle cerebral artery, and unruptured intracranial aneurysms. In addition, the reference lists of the retrieved publications were manually checked to determine other potential qualifying trials that should be included. This process was repeated until no more articles were identified. The meta-analysis was conducted in accordance with the acknowledged the prioritized reported items for systematic review and meta-analysis (PRISMA) guidelines. $^{13}$

\section{Inclusion and Exclusion Criteria}

If an article met the following PICOS criteria, it was considered eligible for incorporation into the current metaanalysis: (I) population: limited to patients with unruptured
MCAAs; (II) intervention: only endovascular coiling and surgical clipping were used for treating unruptured MCAAs; (III) comparison: the outcomes about the procedure-related complications were compared; (IV) outcome measures: one or more of the following outcomes were reported: retreatment, postoperative death, postoperative complete occlusion, modified Rankin scale (mRS), Glasgow Outcome Scale (GOS), postoperative surgical complications including bleeding, infarction, and thrombus without infarction; and (V) the full-text article was published in English.

The exclusion criteria were as follows: (I) an imbalance of clinical characteristics or absence of baseline information and unclear outcome data; (II) conference or commentary articles and letters to the editor; (III) animal trials; (IV) case series, systematic reviews, and meta-analyses.

\section{Data Extraction and Outcome Measures}

Two of the reviewers independently extracted data from the included studies. The following essential information was captured: the first author name, publication year, sample size, study design, outcomes and other relevant data, such as patient characteristics and the literature quality scores. The extracted data, including the median age and range and the size of the trial, were input into the designed standardized table. When there were differences in opinion, a third reviewer had the final decision. The outcome measurements were retreatment, postoperative death, postoperative complete occlusion, mRS or GOS. Complications included the rates of complications, bleeding, infarction, and thrombus without infarction.

\section{Statistical Analysis}

STATA version 11.0 was used for statistical analyses. Heterogeneity across trials was identified using $\mathrm{I}^{2}$ statistics; $\mathrm{I}^{2}>50 \%$ was considered high heterogeneity, and a metaanalysis using a random-effect model was performed for these studies according to the Cochrane Handbook for Systematic Reviews of Interventions (version 5.1.0). Otherwise, the fixed-effect model was performed. The results of categorical outcomes (retreatment, death, postoperative completed occlusion, mRS, GOS and complications including bleeding, infarction, and thrombus without infarction) were expressed as odds ratios (ORs) or rate differences (RDs) with 95\% confidence intervals (CIs). A p-value $<0.05$ was regarded as statistically significant. 


\section{Results}

\section{Search Results}

The selection process is illustrated in Figure 1; the original database (Cochrane Library, Medline, PubMed, and EMBASE) search yielded 1367 records. Of them, 112 were excluded for various reasons (unavailable data, case reports, reviews, and irrelevant articles). The full texts of the remaining 13 articles were reviewed. We excluded 7 articles because they did not compare endovascular coiling and surgical clipping in patients with unruptured MCAAs. Finally, six studies ${ }^{7,14-18}$ were included in the present meta-analysis.

\section{Quality Assessment and Study Characteristics}

The Newcastle-Ottawa Scale (NOS) was used to evaluate the quality of the included non-RCTs (nonrandomized controlled trials); the quality assessment was conducted separately by two reviewers. When there were differences of opinion,

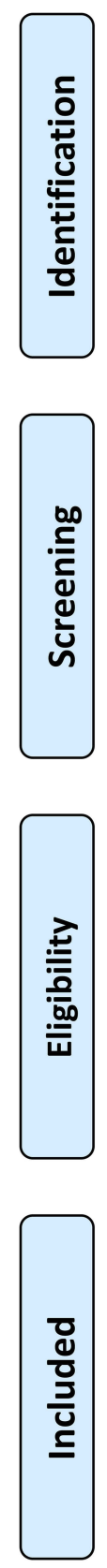

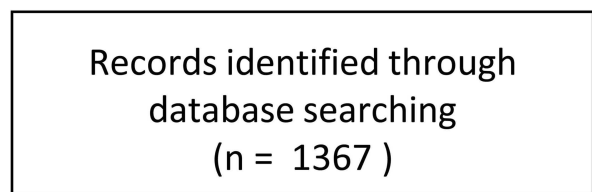

$$
(n=1367)
$$

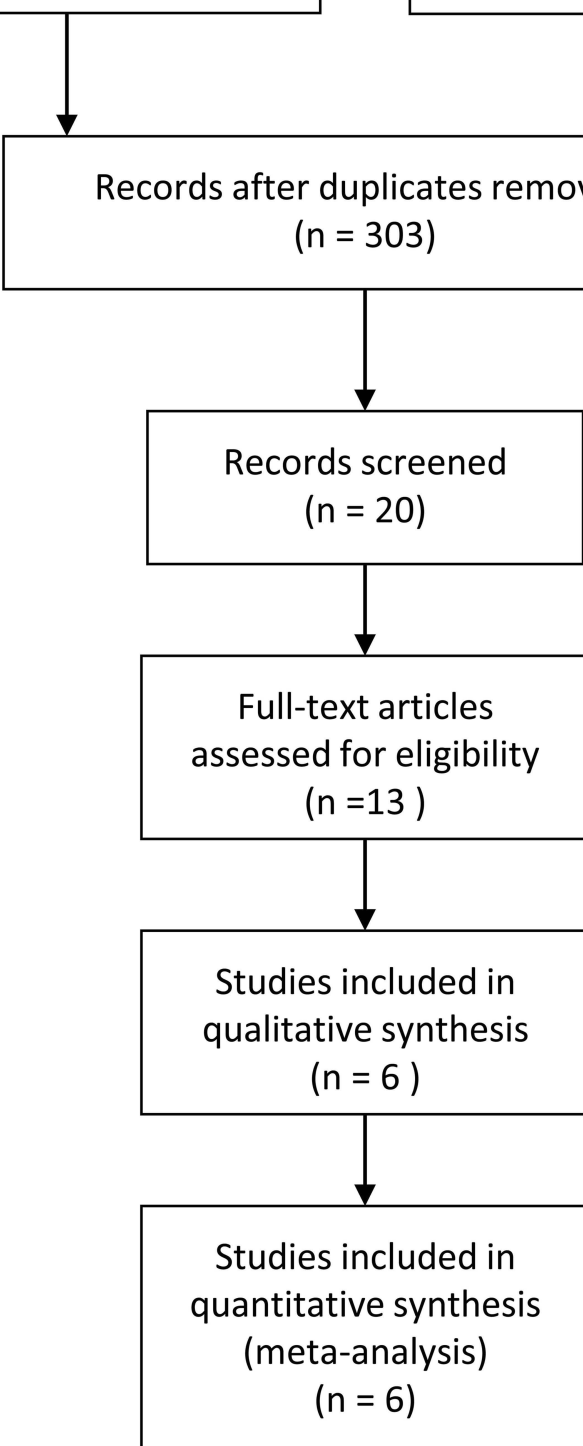

Additional records identified through other sources

$$
(n=0)
$$


another senior author was involved until disagreements were resolved by consensus. The study scores for all articles are shown in Table 1. The demographic characteristics and details concerning the types of studies included are summarized in Table 2. The studies included in the meta-analysis were published from 1999 to 2016 and involved 789 patients (144 were treated with endovascular coiling, and 645 were treated with surgical clipping); the sample sizes varied from 45 to 311 . The studies were from Germany, the USA, Korea, Switzerland, and the Czech Republic.

\section{Outcomes of the Meta-Analysis Retreatment}

Figure 2 shows the postoperative retreatment results. In two publications, 119 and 29 patients were enrolled in the surgical clipping or endovascular coiling groups, respectively. There was a highly significant difference between the clipping group and the coiling group (heterogeneity $\mathrm{P}=0.303 ; \mathrm{I}^{2}=5.8 \%$; OR $=104.926$; $95 \% \mathrm{CI}: 12.931$ to $851.379 ; \mathrm{P}<0.001)$; the rate of retreatment in the clipping group was significantly lower than that in the endovascular treatment group.

\section{Postoperative Deaths}

A comparison of postoperative deaths between the two groups was conducted in four of the included studies.
The results showed that there was no significant difference in deaths between patients treated with clipping and coiling ( 0 of $334(0.00 \%)$ vs 1 of $79(1.27 \%)$; heterogeneity $\mathrm{P}=0.899 ; \mathrm{I}^{2}=0.0 \% ; \mathrm{RD}=0.012,95 \% \mathrm{CI}:-0.030$ to $0.055 ; \mathrm{P}=0.567$; Figure 3).

\section{Postoperative Occlusion (Complete)}

The rate of postoperative complete occlusion was significantly higher in the surgical clipping group than in the endovascular coiling group (90 of $112(80.36 \%$ ) vs 40 of 56 (71.43\%); heterogeneity $\mathrm{P}=0.803 ; \mathrm{I}^{2}=0.0 \% ; \mathrm{OR}=0.349$, 95\% CI: 0.140 to $0.872 ; \mathrm{P}=0.024$; Figure 4 ).

\section{Postoperative Surgical Complications and Specific Complications}

Five articles reported a comparison of postoperative surgical complications between the two groups. There was no heterogeneity in the statistical results of the pooled literature $\left(\mathrm{I}^{2}=0.0 \% ; \mathrm{P}=0.569\right)$. The results of the fixed effect model showed that the clipping group achieved a lower rate of postoperative surgical complications than the endovascular coiling group (13 of $537(2.42 \%)$ vs 12 of 123 (9.76\%); OR = 3.157; 95\% CI: 1.239 to $8.048 ; \mathrm{P}=0.016$; Figure 5). Besides, patients undergoing surgical clipping had a significantly lower rate of postoperative thrombus

Table I Quality Assessment Scores of the Included Studies

\begin{tabular}{|c|c|c|c|c|c|}
\hline \multirow[t]{2}{*}{ Study, Year } & \multirow[t]{2}{*}{ Design } & \multicolumn{4}{|c|}{ Newcastle-Ottawa Scale } \\
\hline & & Selection & Comparability & Exposure & Total Scores \\
\hline Dammann et al, ${ }^{14} 2014$ & Retrospective cohort study & 3 & 2 & I & 6 \\
\hline Diaz et al, ${ }^{15} 2014$ & Retrospective cohort study & 3 & 2 & I & 6 \\
\hline Güresir et al, ${ }^{7} 201 \mathrm{I}$ & Prospective cohort study & 2 & 2 & I & 5 \\
\hline Jang et al, ${ }^{16} 2015$ & Retrospective cohort study & 2 & 2 & I & 5 \\
\hline Regli et al, ${ }^{17} 1999$ & Prospective cohort study & 2 & 2 & 2 & 6 \\
\hline Steklacova et al, ${ }^{18} 2016$ & Retrospective cohort study & 3 & 2 & 2 & 7 \\
\hline
\end{tabular}

Table 2 Overview of Included Studies

\begin{tabular}{|c|c|c|c|c|c|c|c|c|c|}
\hline \multirow[t]{2}{*}{ Author } & \multirow[t]{2}{*}{ Country } & \multirow[t]{2}{*}{ Years } & \multirow{2}{*}{$\begin{array}{l}\text { Enrollment } \\
\text { Period }\end{array}$} & \multirow[t]{2}{*}{ Study Design } & \multicolumn{2}{|c|}{ Participants (n) } & \multicolumn{2}{|c|}{ Age (Mean \pm Standard) } & \multirow{2}{*}{$\begin{array}{l}\text { NOS } \\
\text { Scores }\end{array}$} \\
\hline & & & & & Coil & Clip & Coil & Clip & \\
\hline Dammann et al ${ }^{14}$ & Germany & 2014 & $2006-2010$ & Retrospective & 16 & 87 & 54 & 53.7 & 6 \\
\hline Diaz el al ${ }^{15}$ & USA & 2014 & $2005-2010$ & Retrospective & 40 & 25 & NA & NA & 6 \\
\hline Güresir et $\mathrm{al}^{7}$ & Germany & 2011 & 1999-2009 & Prospective & 21 & 108 & NA & NA & 5 \\
\hline Jang et $\mathrm{al}^{16}$ & Korea & 2015 & $1999-2013$ & Retrospective & 25 & 286 & NA & NA & 5 \\
\hline Regli et al ${ }^{17}$ & Switzerland & 1999 & $1993-1997$ & Prospective & 13 & 32 & NA & NA & 6 \\
\hline Steklacova et al $\left.\right|^{18}$ & Czech & 2016 & $2000-2013$ & Retrospective & 29 & 107 & NA & NA & 7 \\
\hline
\end{tabular}

Abbreviation: NA, not available. 


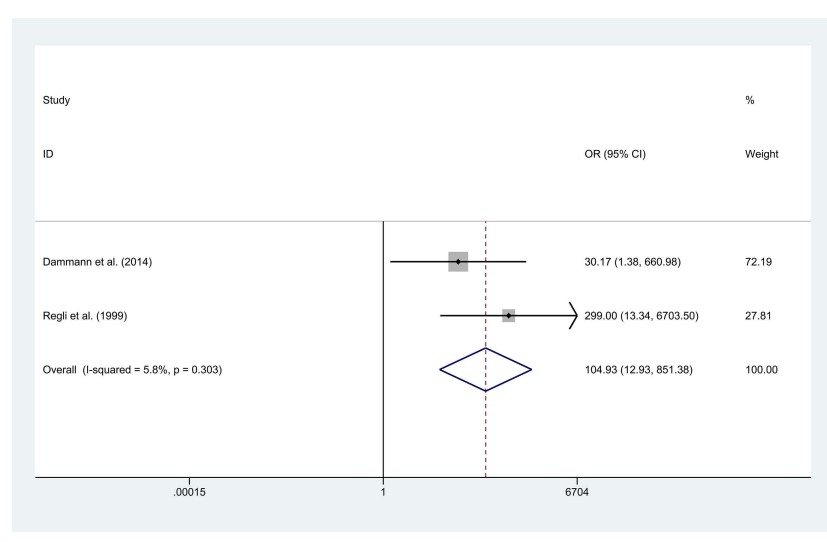

Figure 2 Forest plot of odds ratio (OR) of retreatment with endovascular coiling vs. surgical clipping.

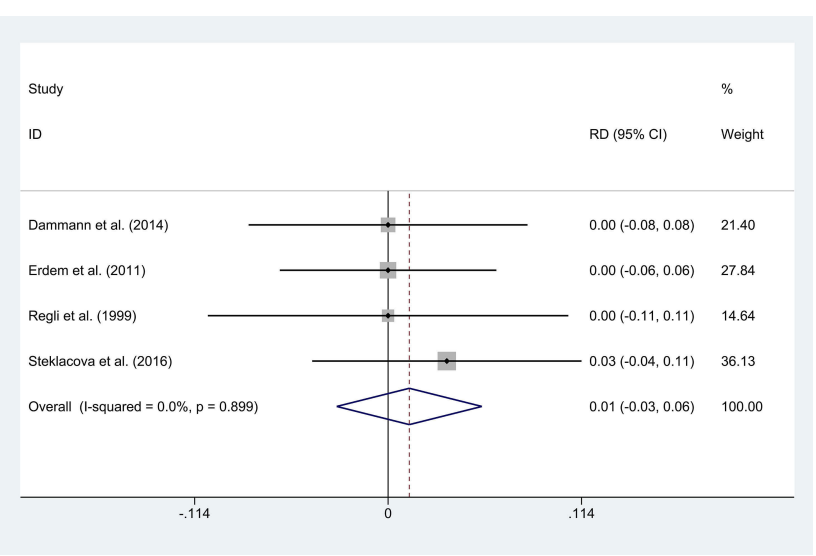

Figure 3 Forest plot of rate difference (RD) of postoperative death with endovascular coiling vs. surgical clipping.

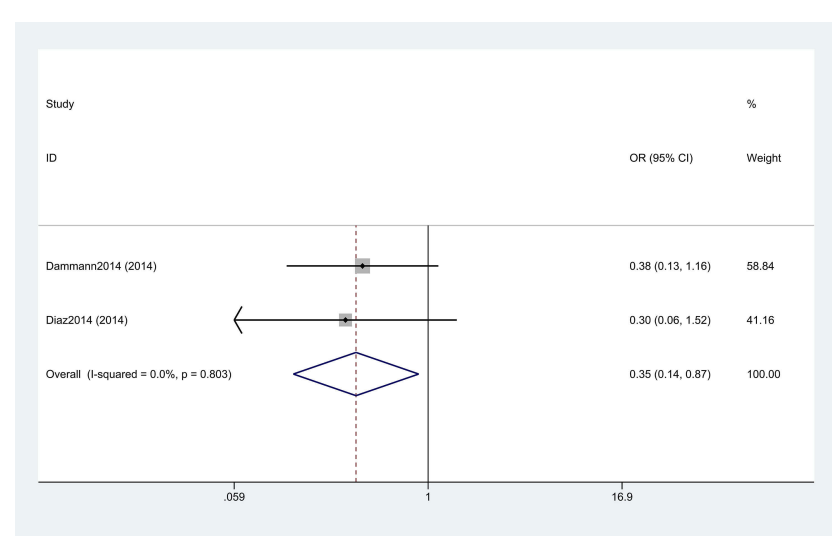

Figure 4 Forest plot of odds ratio (OR) of postoperative completed occlusion with endovascular coiling vs. surgical clipping.

without infarction than patients undergoing coiling ( 2 of $240(0.83 \%)$ vs 5 of $90(5.56 \%)$; heterogeneity $\mathrm{P}=0.390$; $\mathrm{I}^{2}=0.0 \% ; \mathrm{OR}=4.905,95 \%$ CI: 1.097 to $21.933 ; \mathrm{P}=0.037$; Figure 6). Furthermore, no significant difference in

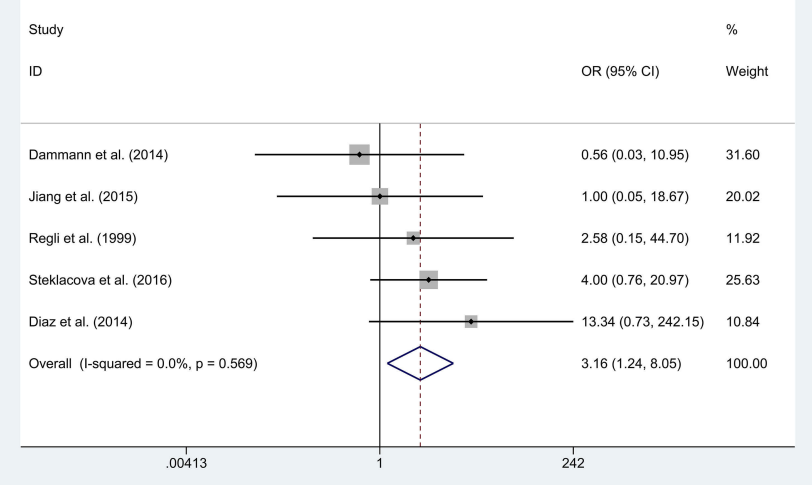

Figure 5 Forest plot of odds ratio (OR) of postoperative surgical complication with endovascular coiling vs. surgical clipping.

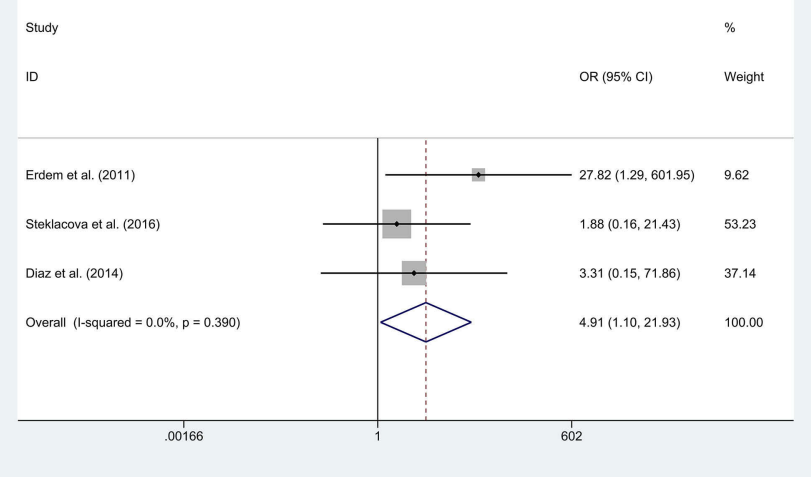

Figure 6 Forest plot of odds ratio (OR) of postoperative thrombus without infarction with endovascular coiling vs. surgical clipping.

postoperative bleed at short-term follow-up $(\mathrm{RD}=0.012$, 95\% CI: -0.040 to $0.063 ; \mathrm{P}=0.658$ ), postoperative bleeding at long-term follow-up ( $\mathrm{RD}=-0.002,95 \% \mathrm{CI}$ : -0.045 to $0.041 ; \mathrm{P}=0.927)$, or infraction $(\mathrm{RD}=0.020,95 \%$ CI: -0.026 to $0.066 ; \mathrm{P}=0.401$ ) was observed.

\section{Modified Rankin Scale (mRS) and Glasgow Outcome Scale (GOS)}

The mRS and GOS were used in our article to estimate the independence of patients' in their daily life. During the 30 days after clipping or coiling reported in some studies, a total of 2 articles reported data on the GOS score outcome, and the results showed that GOS $\geq 4$ was significantly associated with clipping (188 of 194 (96.91\%) vs 40 of 45 (88.89\%); OR $=0.250$; $95 \%$ CI: 0.072 to 0.867 ; $\mathrm{P}=0.029$; Figure 7). However, the proportion of patients with an $\mathrm{mRS}>2$ at follow-up was not significantly different between the surgical group and the endovascular group 


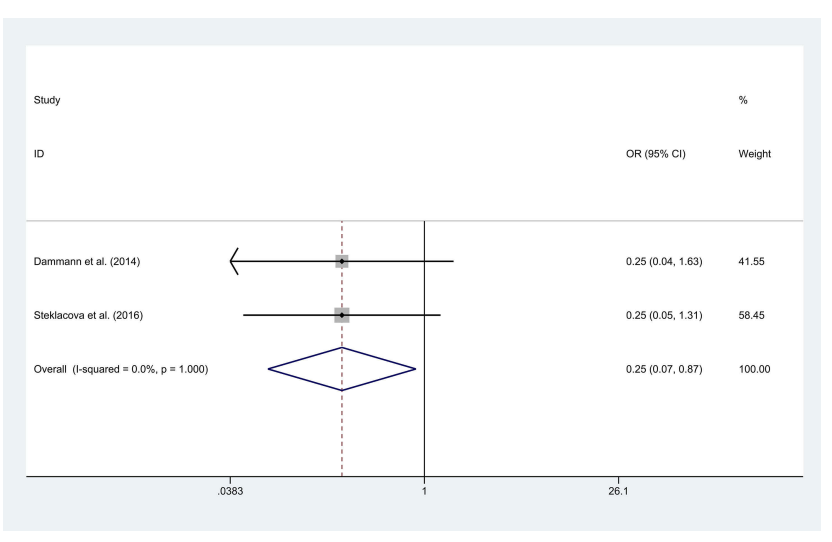

Figure 7 Forest plot of odds ratio (OR) of postoperative Glasgow Outcome Scale (GOS) with endovascular coiling vs. surgical clipping.

(4 of $133(3.01 \%)$ vs 6 of $61(9.83 \%)$; OR $=3.276 ; 95 \%$ CI: 0.690 to $15.555 ; \mathrm{P}=0.135$; Figure 8 ). More details of the results are shown in Table 3.

\section{Discussion}

With the wide use of noninvasive imaging, an increasing number of unruptured cerebral aneurysms have been detected. ${ }^{19}$ The MCA is a common location and it approximately accounts for approximately $20 \%$ of cerebral aneurysms. ${ }^{20}$ Currently, endovascular coiling and surgical clipping have been the primary therapeutic strategies. Endovascular coiling is a minimally invasive treatment in which MCAA occlusion is completed through the blood vessel, while surgical clipping involves a craniotomy and clip placement on the lesion vessel to occlude the MCAA. The goal of therapy is 2-fold: first, the therapeutic method must attain radiographic evidence of aneurysm occlusion to prevent future rupture risk. Second, the intervention risk must be lower than the natural risk of aneurysmal rupture.

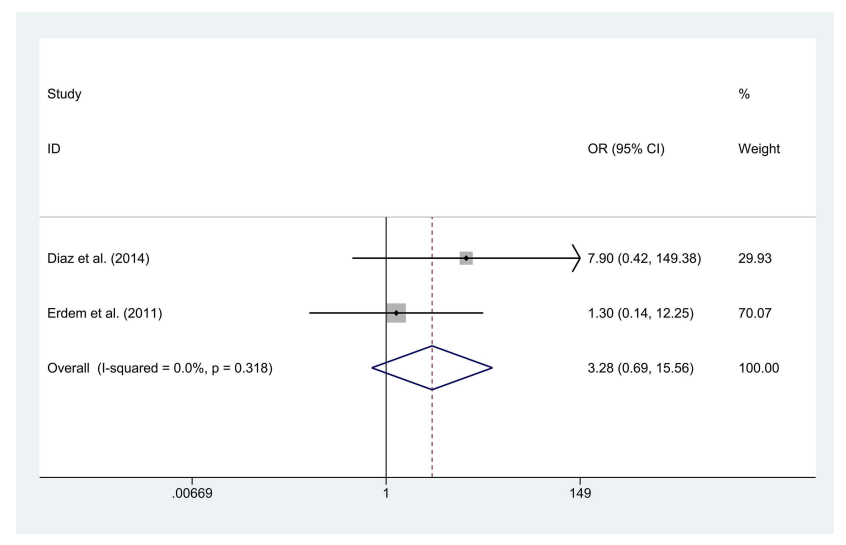

Figure 8 Forest plot of odds ratio (OR) of postoperative modified Rankin scale (mRS) with endovascular coiling vs. surgical clipping.
Although endovascular coiling and surgical clipping have been used to prevent MCAA rupture, there is no exact evidence regarding which therapeutic strategy is better for patients with unruptured MCAAs. We compared the efficiency and safety of these two procedures, given the present conditions, to determine which treatment was better for patients with unruptured MCAAs. The clinical outcomes evaluated included efficacy (retreatment and completed occlusion) and safety outcomes (death, surgical complication, mRS, and GOS).

Gelach et $\mathrm{al}^{21}$ reported that the incidence of postoperative complete occlusion was $66.7 \%$ in the endovascular group, while it was significantly higher $(93.6 \%)$ in the surgical clipping group. Brilstra et $\mathrm{al}^{22}$ also reported that surgical clipping (16/33) was associated with a higher rate of complete occlusion than endovascular coiling. $(36 / 37, \mathrm{P}<0.001)$. Similar to several previously published articles, our analysis found that surgical clipping could achieve a higher rate of complete occlusion compared to endovascular coiling. Besides, to evaluate and compare postoperative complications of surgical clipping versus endovascular coiling for MCAAs, several publications, including our own, have shown endovascular coiling to be related to a higher rate of complications compared to surgical clipping $(\mathrm{OR}=3.157$; 95\% CI: 1.239 to $8.048 ; \mathrm{P}=0.016$ ), which seems to stem from the rate of postoperative thrombus without infarction $(\mathrm{OR}=4.905,95 \% \mathrm{CI}: 1.097$ to $21.933 ; \mathrm{P}=0.037)$.

In previous publications, Dize et $\mathrm{al}^{15}$ reported the procedural results of 90 patients with unruptured MCAAs and found that 7 patients who received the coiling procedure required retreatment compared with 0 patients who received the clipping procedure. Furthermore, in the trial of CARAT (cerebral aneurysm rupture after treatment), ${ }^{23}$ the rates of retreatment were $13.3 \%$ and $2.6 \%$ in the endovascular coiling and surgical clipping groups, respectively, at the first-year follow-up. Similar results were observed in our study, and retreatment rates in the clipping group were significantly lower than those in the coiling group $(\mathrm{OR}=104.926$; 95\% CI: 12.931 to $851.379 ; \mathrm{P}<0.001)$. In fact, there were significant differences in the incidence rates of complete occlusion and complications between those who received endovascular treatment and those who received surgical treatment, which may have affected treatment durability. In addition, it has been documented that endovascular coiling was associated with a higher rate of thromboembolic events, with both the coil mass and catheter approaches, than surgical clipping. 
Table 3 Meta-Analysis Results

\begin{tabular}{|c|c|c|c|c|c|c|c|c|}
\hline \multirow[t]{2}{*}{ Outcome } & \multirow[t]{2}{*}{ Studies } & \multicolumn{2}{|c|}{ Groups } & \multicolumn{3}{|l|}{ Overall Effect } & \multicolumn{2}{|c|}{ Heterogeneity } \\
\hline & & Clip & Coil & Effect Estimate & $95 \% \mathrm{Cl}$ & p-Value & $I^{2}(\%)$ & p-Value \\
\hline Retreatment & 2 & 119 & 29 & 104.926 & $|2.93|-85 \mid .379$ & $<0.001$ & $5.8 \%$ & 0.303 \\
\hline Postoperative death & 4 & 334 & 79 & 0.012 & $-0.030-0.055$ & 0.567 & $0.0 \%$ & 0.899 \\
\hline Postoperative bleed (short term) & 2 & 133 & 61 & 0.012 & $-0.040-0.063$ & 0.658 & $0.0 \%$ & 0.623 \\
\hline Postoperative bleed (long term) at follow & 2 & 394 & 46 & -0.002 & $-0.045-0.04 \mid$ & 0.927 & $0.0 \%$ & 0.934 \\
\hline Post-operative occlusion (complete) & 2 & 112 & 56 & 0.349 & $0.140-0.872$ & 0.024 & $0.0 \%$ & 0.803 \\
\hline MRS $>2$ at follow & 2 & 133 & 61 & 3.276 & $0.690-15.555$ & 0.135 & $0.0 \%$ & 0.318 \\
\hline GOS (4-5) at follow & 2 & 194 & 45 & 0.250 & $0.072-0.867$ & 0.029 & $0.0 \%$ & 1.000 \\
\hline Postoperative surgical complications & 5 & 537 & 123 & 3.157 & $1.239-8.048$ & 0.016 & $0.0 \%$ & 0.569 \\
\hline Postoperative Thrombus w/o Infraction & 3 & 240 & 90 & 4.905 & $1.097-21.933$ & 0.037 & $0.0 \%$ & 0.390 \\
\hline Infraction & 3 & 497 & 75 & 0.020 & $-0.026-0.066$ & 0.401 & $27.7 \%$ & 0.251 \\
\hline
\end{tabular}

Note: Bold font indicates that the p-value of a result was less than 0.05 and regarded as statistically significant.

Abbreviations: MRS, modified Rankin scale; GOS, Glasgow Outcome Scale; w/o, without.

The methods of functional outcome measurement were disparate for both the endovascular coiling and surgical clipping publications. Some articles reported the GOS, while others reported the mRS. To assess and compare interventional safety for endovascular coiling versus surgical clipping of unruptured MCAAs, both the GOS and mRS were evaluated in our studies. This meta-analysis demonstrated that surgical clipping was associated with a higher rate of GOS $\geq$ 4 than endovascular coiling. Regarding the endpoint of mRS $>2$, although two publications reported this outcome, the data were pooled by a fixed effects model to demonstrate that no significant difference was found between treatment groups; however, the endovascular coiling group was associated with more than three times the number of patients with $\mathrm{mRS}>2$ compared to the surgical clipping group (9.83\% VS 3.01\%). Furthermore, Diaz et al $^{15}$ retrospectively reviewed 65 patients with unruptured MCAAs and revealed that endovascular coiling was associated with a higher rate of $\mathrm{mRS}>2$ than surgical clipping ( $12.5 \%$ VS $0 \%, \mathrm{P}<0.01)$. We speculated that this may be due to the relatively small sample size of the included literature, therefore, more RCTs with longterm follow-up are necessary in the future.

Aneurysms in distal arterial segments are often not amenable to endovascular therapy, and surgical therapy may be preferred in these circumstances. ${ }^{24}$ Endovascular treatment is often the preferred technique for posterior circulation aneurysms, which are accessible by angiograms but are harder to access surgically. ${ }^{25}$ In contrast, aneurysms at the MCA bifurcation and wide-necked aneurysms are difficult to coil without complications, and surgery may be preferred for these lesions. Endovascular therapy for cerebral aneurysms is evolving; new techniques are under investigation, including stent-assisted coiling, balloon-assisted coiling, flow diverters and disruptors, and new embolic materials offer promise that aneurysms previously considered not amenable to therapy will be treatable in the future. ${ }^{26,27}$ Our research has the following limitations. First, the current study only compared perioperative clinical outcomes relevant to the safety and efficiency of the two approaches due to relatively little data on these outcomes with the same long-term follow-up period. Second, some heterogeneity was found among the included trials regarding the study protocols, patient characteristics, and definitions of clinical endpoints. Finally, the main inclusion and exclusion criteria of the trials and the characteristics of the participant were different in the included studies, potentially causing bias.

\section{Conclusion}

Although this study has inherent limitations, surgical clipping of unruptured MCAAs resulted in significantly higher complete aneurysm occlusion and GOS $\geq 4$ rates and was associated with a lower incidence of retreatment and complication, especially for postoperative thrombus without infarction. Therefore, the effect induced by the surgical clipping of unruptured MCAAs remains superior to that induced by endovascular coiling; surgical clipping should be regarded as the first choice of treatment for unruptured MCAAs.

\section{Abbreviations}

PRISMA, preferred reporting items for systematic reviews and meta-analyses; CARAT, cerebral aneurysm rupture after treatment; CIs, confidence intervals; ORs, odds ratios; RCT, randomized controlled trial; RDs, rate differences; MCAAs, middle cerebral artery aneurysms; MCA, 
middle cerebral artery; mRS, modified Rankin scale; NOS, Newcastle-Ottawa Scale; SAH, subarachnoid hemorrhage; GOS, Glasgow Outcome Scale.

\section{Funding}

Our work was supported by funding from the National Natural Science Foundation of China (no. 81570507, XYY).

\section{Disclosure}

The authors have declared that no competing interests exist.

\section{References}

1. Molyneux A, Kerr R, Stratton I, et al. International Subarachnoid Aneurysm Trial (ISAT) of neurosurgical clipping versus endovascular coiling in 2143 patients with ruptured intracranial aneurysms: a randomised trial. Lancet (London, England). 2002;360 (9342):1267-1274. doi:10.1016/s0140-6736(02)11314-6

2. Molyneux AJ, Kerr RS, Yu LM, et al. International subarachnoid aneurysm trial (ISAT) of neurosurgical clipping versus endovascular coiling in 2143 patients with ruptured intracranial aneurysms: a randomised comparison of effects on survival, dependency, seizures, rebleeding, subgroups, and aneurysm occlusion. Lancet (London, England). 2005;366(9488):809-817. doi:10.1016/S01406736(05)67214-5

3. Spetzler RF, McDougall CG, Albuquerque FC, et al. The barrow ruptured aneurysm trial: 3-year results. J Neurosurg. 2013;119 (1):146-157. doi:10.3171/2013.3.JNS12683

4. Zaidat OO, Castonguay AC, Teleb MS, et al. Middle cerebral artery aneurysm endovascular and surgical therapies: comprehensive literature review and local experience. Neurosurg Clin N Am. 2014;25 (3):455-469. doi:10.1016/j.nec.2014.04.005

5. Lu HT, Tan H-Q, Bin-Xian G, et al. Risk factors for multiple intracranial aneurysms rupture: a retrospective study. Clin Neurol Neurosurg. 2013;115(6):690-694.

6 . Yoon W. Current update on the randomized controlled trials of intracranial aneurysms. Neurointervention. 2011;6(1):1-5. doi:10.5469/neuroint.2011.6.1.1

7. Güresir E, Schuss P, Berkefeld J, Vatter H, Seifert V. Treatment results for complex middle cerebral artery aneurysms. A prospective single-center series. Acta Neurochir (Wien). 2011;153(6):1247-1252. doi:10.1007/s00701-011-1008-3

8. Flamm ES, Grigorian AA, Marcovici A. Multifactorial analysis of surgical outcome in patients with unruptured middle cerebral artery aneurysms. Ann Surg. 2000;232(4):570-575. doi:10.1097/00000658200010000-00012

9. Haug T, Sorteberg A, Sorteberg W, et al. Surgical repair of unruptured and ruptured middle cerebral artery aneurysms: impact on cognitive functioning and health-related quality of life. Neurosurgery. 2009;64 (3):412-420; discussion 421-412. doi:10.1227/01.NEU.00003389 $52.13880 .4 \mathrm{E}$

10. Rodríguez-Hernández A, Sughrue ME, Akhavan S, HabdankKolaczkowski J, Lawton MT. Current management of middle cerebral artery aneurysms: surgical results with a "clip first" policy. Neurosurgery. 2013;72(3):415-427. doi:10.1227/NEU.0b013e318 2804aa2

11. Hwang JS, Hyun MK, Lee HJ, et al. Endovascular coiling versus neurosurgical clipping in patients with unruptured intracranial aneurysm: a systematic review. BMC Neurol. 2012;12(undefined):99.
12. Mortimer AM, Bradley MD, Mews P, Molyneux AJ, Renowden SA. Endovascular treatment of 300 consecutive middle cerebral artery aneurysms: clinical and radiologic outcomes. Am J Neuroradiol. 2014;35(4):706-714. doi:10.3174/ajnr.A3776

13. Liberati A, Altman DG, Tetzlaff J, et al. The PRISMA statement for reporting systematic reviews and meta-analyses of studies that evaluate health care interventions: explanation and elaboration. PLoS Med. 2009;6(4):e1-e34.

14. Dammann P, Schoemberg T, Müller O, et al. Outcome for unruptured middle cerebral artery aneurysm treatment: surgical and endovascular approach in a single center. Neurosurg Rev. 2014;37(4):643-651. doi:10.1007/s10143-014-0563-5

15. Diaz OM, Rangel-Castilla L, Barber S, et al. Middle cerebral artery aneurysms: a single-center series comparing endovascular and surgical treatment. World Neurosurg. 2014;81(2):322-329. doi:10.1016/j. wneu.2012.12.011

16. Jang EW, Kim YB, Chung J, et al. Clinical risk factors affecting procedure-related major neurological complications in unruptured intracranial aneurysms. Yonsei Med J. 2015;56(4):987-992.

17. Regli L, Uske A, de Tribolet N. Endovascular coil placement compared with surgical clipping for the treatment of unruptured middle cerebral artery aneurysms: a consecutive series. J Neurosurg. 1999;90 (6):1025-1030. doi:10.3171/jns.1999.90.6.1025

18. Steklacova A, Bradac O, Charvat F, De Lacy P, Benes V. "Clip first" policy in management of intracranial MCA aneurysms: single-centre experience with a systematic review of literature. Acta Neurochir (Wien). 2016;158(3):533-546; discussion 546. doi:10.1007/s00701015-2687-y

19. Brinjikji W, Rabinstein AA, Nasr DM, et al. Better outcomes with treatment by coiling relative to clipping of unruptured intracranial aneurysms in the United States, 2001-2008. AJNR Am J Neuroradiol. 2011;32(6):1071-1075. doi:10.3174/ajnr.A2453

20. Molyneux A, Kerr R, Stratton I, et al. International Subarachnoid Aneurysm Trial (ISAT) of neurosurgical clipping versus endovascular coiling in 2143 patients with ruptured intracranial aneurysms: a randomized trial. J Stroke Cerebrovasc Dis. 2002;11(6):304-314. doi:10.1053/jscd.2002.130390

21. Gerlach R, Beck J, Setzer M, et al. Treatment related morbidity of unruptured intracranial aneurysms: results of a prospective single centre series with an interdisciplinary approach over a 6 year period (1999-2005). J Neurol Neurosurg Psychiatry. 2007;78(8):864-871. doi:10.1136/jnnp.2006.106823

22. Brilstra EH, Rinkel GJ, van der Graaf Y, et al. Quality of life after treatment of unruptured intracranial aneurysms by neurosurgical clipping or by embolisation with coils. A prospective, observational study. Cerebrovasc Dis. 2004;17(1):44-52. doi:10.1159/000073897

23. CARAT Investigator. Rates of delayed rebleeding from intracranial aneurysms are low after surgical and endovascular treatment. Stroke. 2006;37(6):1437-1442. doi:10.1161/01.STR.0000221331.01830.ce

24. Tateshima S, Murayama Y, Gobin YP, et al. Endovascular treatment of basilar tip aneurysms using Guglielmi detachable coils: anatomic and clinical outcomes in 73 patients from a single institution. Neurosurgery. 2000;47(6):1332-1339; discussion 1339-1342. doi:10.1097/00006123-200012000-00012

25. Suzuki S, Tateshima S, Jahan R, et al. Endovascular treatment of middle cerebral artery aneurysms with detachable coils: angiographic and clinical outcomes in 115 consecutive patients. Neurosurgery. 2009;64(5):876-888; discussion 888-879. doi:10.1227/01.NEU. 0000343534.05655 .37

26. Laurent P, Wakhloo AK. Endovascular treatment of intracranial aneurysms: current status. Stroke. 2013;44(7):2046-2054. doi:10.116 1/STROKEAHA.113.000733

27. Zubillaga AF, Guglielmi G, Vinuela F, Duckwiler GR. Endovascular occlusion of intracranial aneurysms with electrically detachable coils: correlation of aneurysm neck size and treatment results. AJNR Am J Neuroradiol. 1994;15(5):815. 


\section{Publish your work in this journal}

Neuropsychiatric Disease and Treatment is an international, peerreviewed journal of clinical therapeutics and pharmacology focusing on concise rapid reporting of clinical or pre-clinical studies on a range of neuropsychiatric and neurological disorders. This journal is indexed on PubMed Central, the 'PsycINFO' database and CAS, and is the official journal of The International Neuropsychiatric Association (INA). The manuscript management system is completely online and includes a very quick and fair peer-review system, which is all easy to use. Visit http://www.dovepress.com/testimonials.php to read real quotes from published authors. 